УдК 1/14:316+422:316.3

\title{
ИННОВАЦИОННОЕ ПРОСТРАНСТВО И ОБЩЕСТВО: ПОНЯТИЯ, ФАКТОРЫ РАЗВИТИЯ
}

\author{
Демидова Марина Владимировна, \\ demidovamv@rambler.ru
}
Саратовский национальный исследовательский государственный университет им. Н.Г. Чернышевского, Россия, 410012, г. Саратов, ул. Астраханская, 83. Демидова Марина Владимировна, кандидат философских наук, магистрант Саратовского нацио-
нального исследовательского государственного университета им. Н.Г. Чернышевского.

\begin{abstract}
Актуальность. Развитие науки и техники оказывает влияние на структуру и организацию современного общества, что способствует развитию инновационного пространства. Изучение категории «инновационное пространство» в настоящее время ограничено преимущественно рамками экономической науки, в связи с чем исследователями часто не принимаются во внимание закономерности социального развития. Ограничение инновационного пространства экономическими рамками может привести к риску отождествления оценки социального развития с оценкой экономического развития общества. Поэтому требуется определить инновационное пространство с более общих социально-философских позиций. Цель: изучение и определение инновационного пространства современного общества с позиций философии. Методы. Междисциплинарная специфика инновационных преобразований ориентирует на рассмотрение изучаемых вопросов в трансдисциплинарном аспекте, т. е. на основе философских подходов и методов исследования инновационного пространства социума. Поэтому методологическую базу исследовательской работы составили диалектический, культурно-цивилизационный, социосинергетический подходы, общенаучные методы, концепция энактивности. Результаты. Прослежена эволюция инноваций во взаимосвязи с развитием общества. Выявлен основной фактор социально-экономического и социального взаимодействия в инновационном пространстве общества - «символический капитал» как «кредит доверия», т. к. доверие определяет вовлечённость (включённость) людей в социальный процесс. Наличие доверия к инновациям, в том числе социальным, способствует развитию общества. Посредством выявления взаимосвязи модернизации с социальными инновациями автором впервые сформулировано понятие «инновационное пространство общества», определяемое как форма социальной самоорганизации, направленной на развитие общественных отношений, осуществляемое посредством инновационных преобразований. Вывод. Инновационное пространство есть инвариант социального пространства; в связи с социальной детерминированностью инновационного пространства его следует определять исходя из особенностей функционирования социального пространства. $B$ этом случае возможно получение более полного представления об инновационной системе, что в перспективе позволит разработать модели управления инновационным пространством, способствующие прогрессивному развитию общества. Полученные результаты исследования могут быть полезны в социальных, управленческих, экономических, философских науках.
\end{abstract}

Ключевые слова: Инновации, инновационное пространство, развитие общества, символический капитал, доверие, модернизация, социальные технологии, факторы развития, социальное пространство, социальная самоорганизация, социальный прогресс, П. Бурдьё, энактивность.

Развитие науки и техники приводит к трансформациям в устройстве и организации общества. Осуществление этих процессов происходит посредством новых технологий, что способствует развитию инновационного пространства. 
Наиболее общее определение понятия «пространство» принадлежит философии, оно трактуется как «объективная всеобщая форма бытия материального мира, характеризующая его протяжённость, структурность, сосуществование и взаимодействие его внутренних элементов» [1, с. 541]. Понятие «инновация» чаще применяется в экономике и определяется как «конечный результат инновационной деятельности, получивший реализацию в виде нового или усовершенствованного продукта, реализуемого на рынке, нового или усовершенствованного технологического процесса, используемого в практической деятельности» [2, с. 19].

Изучение категории «инновационное пространство» в настоящее время ограничено преимущественно рамками экономической науки, лишь иногда оно осуществляются применительно к социально-экономической деятельности и в целом направлено на получение знаний о возможностях получения экономически эффективного результата. Исследования данной категории с позиций философии нами не обнаружены совсем, лишь в некоторых работах авторы применяют философскую методологию (диалектический подход) к исследованию социально-экономических инноваций. Поэтому основной целью нашего исследования являются изучение и определение инновационного пространства современного общества с позиций философии.

\section{Основные теоретические подходы к исследованию инновационного пространства}

Можем выделить следующие подходы к исследованию инновационного пространства:

1. Экономический подход. Современная экономическая наука связывает формирование инновационного пространства с процессом становления экономики знаний, которая является формой хозяйствования нового типа общества - общества знаний [3], формируемого примерно с 80-х годов $\mathrm{XX}$ в. В это время знания становятся источником экономического роста и «превращаются в стратегический фактор роста, влияющий на структуру общественного производства и организацию экономических и управленческих отношений», что ведёт к формированию инновационного пространства [4, с. 7].

Экономика знаний активизирует инновационные процессы, т. к. «инновационное пространство представляет собой совокупность имеющихся новых знаний, которые необходимо трансформировать в реальный сектор экономики», считает Н.П. Красоченкова [4, с. 8]. По её мнению, роль инновационного пространства, являющегося элементом инновационной системы, заключается «в обеспечении непрерывности процесса преобразования новых знаний в инновации с последующим распространением в реальном секторе» экономики [4, с. 8].

Инновационная система включает в себя: 1) совокупность субъектов инновационной деятельности; 2) правовые, законодательные, финансовые институты; 3) взаимодействие между субъектами инновационной деятельности в процессе создания и реализации новшеств для экономического развития. У каждой инновационной системы есть собственные инновационная среда, представляющая собой совокупность субъектов инновационной деятельности и условия их взаимодействия, и инноваџионная инфраструктура как совокупность различных организационных структур (например, бизнесинкубаторы), способствующих развитию инновационной системы [5, с. 44].

Расширение инновационного пространства напрямую зависит от развития экономики знаний, в которой наиболее экономически выгодными становятся наука и образование, наукоёмкие отрасли сферы услуг. Статистика показывает, что по уровню расходов на научные исследования и разработки к 2015 г. Россия вышла на средний уровень среди экономически развитых стран [5, с. 45-46]. Но, как указывает Н.П. Красоченкова, 
«практика предоставления грантов и государственных заданий выявила следующие недостатки: 1) отсутствие механизма контроля и персональной ответственности за использование нового знания привело к тому, что огромный объём новых знаний не воплощён в инновациях, затраченные ресурсы и полученные результаты не обеспечивают инновационное развитие национальной экономики; 2) отсутствие рыночных отношений при формировании государственного задания изначально программирует ошибки в выборе направления и субъекта генерирования нового знания» [5, с. 45-46].

С позиций экономического подхода исследования инновационного пространства ориентированы на решение задач экономической эффективности инноваций, основным препятствием для которой является невысокий уровень эффективности менеджмента в российской инновационной системе.

2. Социально-экономический подход. В рамках социально-экономического подхода российские исследователи О.Б. Воейкова и В.И. Лячин предприняли попытку формирования целостной концепции организации инновационного пространства, которое является экономической категорией и определяется ими как «системная форма организации объектов инновационной деятельности, основанная на социально-экономических отношениях и направленная на инновационное преобразование действительности, характеризующаяся соответствующей структурой, конфигурацией и территориальной протяжённостью» [6]. С философских позиций данная концепция может представлять интерес в связи с применением исследователями философской методологии: диалектического подхода, центрированного на категориях «развитие», «количество», «качество», «пространство», «время», «часть», «целое» и других, включённых в социально-экономический процесс посредством основных законов диалектического развития.

По мнению О.Б. Воейковой и В.И. Лячина, инновационное пространство представляет собой открытую самоорганизующуюся систему, поэтому является объектом для исследования на основе системного подхода. Системообразующим элементом инновационного пространства является новшество (или инновация), представляющая собой центр, «вокруг которого начинает разворачиваться система элементов, связанных триединой задачей по созданию, производству и реализации этого новшества. Либо это будет уже существующая инновационная система, которая будет достраиваться путём включения в неё новых объектов» [6, с. 1018]. Системообразующая функиия инновационного пространства определяется его протяжённостью, т. к. опосредована причинно-следственными связями его существования, задавая тем самым его функциональную целостность: «исходным отношением для инновационного пространства, в соответствии с представлением об основных функциях инновации и исходя из представления о системных качествах формирующейся постиндустриальной эпохи, является функция изменения или преобразования» [6, с. 1020].

Системообразующий элемент и системообразующая функция в совокупности задают единое функциональное назначение инновационного пространства, которое заключается «в такой организации этого множества объектов, при которой становится возможным инновационное преобразование действительности (а следовательно, сопряжённых с инновационным пространством информационной, социальной, экономической и прочих составляющих)» $[6$, с. 1020].

Инновационное пространство неоднородно, т. к. не все объекты окружающей действительности подвержены инновационным изменениям по причине различной степени восприимчивости к инновациям (т. е. готовности общества воспринимать и реализовывать инновационные решения), которая во многом определяется образовательным уровнем создателей и потребителей инноваций, а также уровнем получаемых ими доходов [7]. 
Преимущества предложенной О.Б. Воейковой и В.И. Лячиным концепции инновационного пространства состоят в выявлении авторами общих принципов структурирования и функционирования инновационного пространства. Но в проблемном поле, очерченном исследователями, всё же преобладает экономический аспект, т. к. цели их исследования направлены на достижение экономического результата. Закономерности структурирования и функционирования современного общества не исследованы, поэтому не включены в содержание предложенной концепции, вероятно, по причине приверженности исследователей идеям марксистской трактовки экономики как базиса общественных отношений.

Обобщив рассмотрение экономического и социально-экономического подходов к определению понятия «инновационное пространство», можем констатировать факт наличия между ними сходств больше, чем отличий. Основным отличием является учёт или неучёт социальных факторов при выявлении инновационных способов достижения экономических целей. Сходства - в ориентации на максимально эффективное применение инновации с целью увеличения прибыли в сфере экономики.

Такое сужение целей исследования может привести к риску отождествления оценки социального развития с оценкой экономического развития, в то время как социальное развитие включает в себя экономическое, т. к. экономическая деятельность является одной их форм деятельности общества - хозяйственной. В современных трактовках термин «общество» понимается как «определённый тип системы, состоящей из разнородных взаимосвязанных элементов и подсистем, свойств и отношений, созданной индивидами на основе механизмов обратной связи, целью которой является реализация экстремальных (максимальных) принципов в жизнедеятельности индивидов с помощью законов, действующих в определённых границах» [8, с. 14]. Экономикой называют «способ организации деятельности людей, направленной на создание благ, необходимых им для потребления. Синонимом этого значения является понятие "хозяйство"» [9, с. 13].

Другими словами, экономическая деятельность является одним из видов деятельности общества. Это значит, что сферы создания и применения инноваций не ограничиваются экономическим сектором деятельности. Поэтому применение экономического и социально-экономического подходов без учёта закономерностей социального развития сужает понимание инновационного пространства и тем самым даёт нам неполное представление об инновационной системе.

Исследования инновационного пространства, осуществляемые с позиций социально-философского подхода, нами не обнаружены. В связи с чем можем сказать об отсутствии в современной науке понятия «социальное инновационное пространство», что не способствует целостному пониманию инновационной системы. Также отсутствуют исследования вопросов взаимодействия инновационного и социального пространств. С учётом приведённых доводов считаем, что для целостного понимания понятия «инновационное пространство» следует, руководствуясь диалектическим подходом, проследить эволюцию инноваций во взаимосвязи с развитием общества. А затем посредством выявления взаимосвязи модернизации с социальными инновациями, определить авторское понятие «инновационное пространство общества».

\section{Развитие теории инноваций и инноватики}

По мнению В.Л. Романова, «соотнесение инновационных процессов с категорией социального означает, что объектом исследования является не только родовое для традиционной инноватики поле предпринимательства, а вся целостная совокупность от- 
ношений, поведения и способов деятельности, образующая среду общественного бытия человека, которая, непрерывно обновляясь, обеспечивает коонтогенез индивидов и филогенез человеческого рода, их взаимообусловленность на различных уровнях и общностных пространствах жизнеустройства людей. Представление этой среды как процесса, в котором движетелем является креативное обновление, выводит на определение предметом ее исследования инновационную составляющую этого процесса» [10].

Известный российский учёный А.И. Пригожин в своём большом труде, посвящённом вопросам нововведений, указал на происхождение понятия «инновация» (от англ. innovation) из культурологии. Ещё в XIX в. инновацией называли процесс адаптации новой нормы культуры или адаптированную норму культуры. И только в начале XX в. стали изучаться закономерности технических нововведений [11, с. 21].

В теории инноваций принято считать, что первое научное исследование, посвящённое изучению вопросов взаимосвязи технического развития с социальным, принадлежит российскому учёному Н.Д. Кондратьеву, который в 1922 г. предположил и обосновал существование так называемых «больших циклов» или «длинных волн». Материальной основой циклов является «изнашивание, смена и расширение основных капитальных благ, требующих длительного времени и огромных затрат для своего производства» [12, с. 218].

Позже эти идеи были развиты с экономических позиций Й. Шумпетером, обосновавшим необходимость для экономического развития особой «предпринимательской функции», которая состоит в осуществлении «новых комбинаций факторов производства». Главное в предпринимательской деятельности - изменения или инновации, благодаря которым осуществляется динамика экономического развития [13]. Й. Шумпетер считается родоначальником инновационных концепций в теории длинных волн экономического развития.

Следующим этапом в развитии теории инноваций стало исследование П. Друкера «Эпоха перерыва постепенности» (1969), где он обобщил результаты развития научнотехнической революции: инновации и новые технологии могут обесценить любые сбережения и инвестиции в «застывшую» технику, подняв роль и цену гибкого, «живого», научно-организованного труда. Согласно П. Друкеру, сегодня производительность создаётся знаниями, они центральный экономический ресурс, порождающий новую экономику как «экономику знаний», а все общество - это «общество знаний» [3].

Следующей вехой в теории нововведений стала книга Г. Менша под названием «Технологический пат» (1975). Пат - это шахматная ситуация на доске, при которой ни один из игроков не может выиграть. «Технологическим патом» он назвал структурный кризис, который является закономерной паузой в поступательном развитии экономики. Его причина - недостаточный запас или отсутствие революционных или базисных, нововведений. Основным фактором внедрения изобретений являются экономические условия [14].

С 1970-х гг. начинает развиваться отдельная область знаний «инноватика»- наука о нововведениях. Активно исследуются различные аспекты нововведений: «вопросы их классификации, выделение последовательных стадий процесса разработки новшества, иерархии видов деятельности, начинающейся с производства научных знаний и заканчивающейся созданием новых продуктов и технологических процессов, длительности инновационного процесса, эффективного управления процессом внедрения нового, проблемы "психологических барьеров" и др. Причины появления еще одной научной области объясняли тем, что мир нововведений не сводится только к технике и технологии» [15]. 
По мнению лауреата Нобелевской премии Ильи Пригожина, инновации должны определяться тремя минимальными требованиями. Первое - необратимость, выражающаяся в нарушении симметрии между прошлым и будущим. Второе - необходимость введения понятия «событие». Третье - некоторые события должны обладать способностью изменять ход эволюции [16]. Поэтому исследование инноваций с позиций социально-философского подхода может позволить выявить взаимосвязь модернизации, инноваций и социального развития.

\section{Модернизация и инновационное пространство социума}

С позиций социально-философского подхода инновации следует понимать как новые или усовершенствованные средства организации деятельности социума. Поэтому целью социально-философского осмысления пространства инноваций является исследование процессов, связанных с созданием и функционированием инноваций, в аспекте их влияния на социальную организацию и выявление тенденций социального развития.

Социально-философская направленность осмысления технологических изменений прекрасно представлена современным российским философом Н.С. Розовым в работе «Когда началась эпоха Модерна и закончилась ли она?» [17], где автором проанализировано развитие общества с позиций модернизации (т. е. технического изменения и обновления), проводимой многоаспектно. Согласно Н.С. Розову, под «модерном» понимают «эпоху, начавшуюся с французского Просвещения XVIII в. и продолжавшуюся до 1970-80-х гг., когда модерн будто бы завершился и началась эпоха “постмодерна". Качественно модерн характеризуют становлением и расцветом национальных государств, растущей верой в науку и прогресс, индустриализацией и урбанизацией, наличием “больших нарративов” (марксизм, фрейдизм), бурным развитием и доминированием идеологий..., а также “модернизмом" в искусстве как устремлённостью к беспрестанному обновлению стилей и форм» [17, с. 67].

В результате исследования Н.С. Розов выделил три этапа модернизации:

1. Модернизация-1 (середина XVII - начало XIX вв.), когда к раннемодерновской европейской бюрократизации добавляется секуляризация, капиталистическая индустриализация и значительный прорыв в демократизации.

2. Модернизация-2 (начало XIX - конец XX вв.) отличается такими значимыми процессами, как доминирование гражданских обществ, основанных на принципах равенства и демократии; преобладание философского и научного знания над религиозным; ставка обществ на обновление и развитие технологий; расцвет идеологий и “больших нарративов”, доминирование идей прогресса и эволюции; быстрая смена стилей, мод, субкультур; становление социальных государств, основными задачами которых становится решение социальных проблем (здравоохранение, экология, социальное и пенсионное обеспечение, забота о детстве, материнстве и т. п.).

3. Модернизация-3 (с начала XXI в.), характеризующаяся динамичной трансформацией глобальных социальных процессов, определить которую можно будет, по мнению Н.С. Розова, только после её завершения [17, с. 72].

Примечательным является выявленный Н.С. Розовым факт становления в XX в. социальных государств. Такая трансформация ориентиров государственного управления приводит к развитию социальных инноваций, необходимых в совершенствовании государства. Их главное отличие от экономических инноваций - ориентированность на эффективность управления, на регулирование социального взаимодействия. 
Исследований, посвящённых теме социальных инноваций, крайне мало. В одном из них социальные инновации рассматриваются как «возможный и наиболее перспективный инструмент гражданского участия и межсекторного партнёрства в решении социальных задач. Под такими инновациями понимаются новые разработки (продукты, услуги, модели, процессы и т. д.), которые удовлетворяют социальные потребности эффективнее в сравнении с существующими, ...обеспечивают повышение способности гражданского общества к самоорганизации и действию» [18, с. 41$]$.

Переход общества к этапу социальной модернизации посредством социальных инноваций представляет собой реализацию постнеклассического идеала рациональности, основывающегося на позиции, согласно которой результат взаимодействия субъекта и объекта взаимодействия зависят от процесса их взаимодействия. Поэтому социальные технологии являются средствами социального взаимодействия, осуществляемого в различных сферах деятельности социума. Эффективность современных социальных взаимодействий напрямую зависит от эффективности социальных технологий.

В настоящее время в связи с формированием социальных государств возрастает значение социальных технологий. Осмысление данных изменений, осуществляемое с позиций социально-философского подхода, неминуемо приводит нас к культурным и цивилизационным аспектам исследования развития общества. Взаимосвязь данных аспектов человеческой деятельности наиболее чётко была объяснена ещё И. Кантом, согласно которому культура есть цель (или реализация свободы), а цивилизация - средство для достижения цели [19]. Позже данную идею развил О. Шпенглер, назвав цивилизацию завершающим этапом в развитии общества, т. к. с её помощью достигнуты цели, поставленные культурой [20]. В связи с чем увеличение количества инноваций как средств деятельности человека (хозяйственной, общественной и других) есть показатель активизации цивилизационных векторов развития современного социума.

В связи с происходящими цивилизационным изменениями всё более проблематичным становится определение понятий «социум» или «общество». Если авторы традиционных определений понятия «социум» в качестве критериев его определения вводили такие индикаторы, как «географическая граница», «общая деятельность», «общие нормы поведения», то современные глобализационные процессы заставляют исследователей сменить индикаторы определения социума. Одна из причин подобной смены, по мнению современного философа В.Б. Устьянцева, - смена типов рациональности: «В классической рациональности... структурность цивилизационного пространства ассоциируется с наличием географических, политических, культурных границ, образующих жизненное пространство отдельных народов. В постнеклассической рациональности при осмыслении пространства цивилизаций... применяется термин «жизнеспособные пространственные структуры». ... Жизненное пространство цивилизации мыслится как особый вид пространственных структур, объединяющий техногенные, социально-политические и ценностные элементы, способные к сохранению и развитию цивилизации» [21, с. 97-98].

В связи с чем можно предположить, что современное трансформирующееся общество определяется многими авторами исходя из преобладающего фактора цивилизационного развития: 1) «постиндустриальное общество» в интерпретации М. Маклюэна: в обществе преобладает производство нематериальных продуктов - услуг, а труд становится преимущественно интеллектуальным [22]; 2) «информационное общество» в интерпретации Д. Белла: общество производит информацию и функционирует на основе применения информационно-коммуникативных технологий [23]; 3) «общество знаний» П. Друкера [3] в интерпретации Э. Тоффлера по сути тождественно «информационному обществу» [24]; 4) «общество потребления», когда, потребляя, общество наращивает производство, согласно теории Ж. Бодрийяра [25]. 
Все представленные трактовки общества относятся к нашей современности. Означает ли это, что кто-то из авторов не прав? Конечно, нет. Скорее, данными исследователями представлены различные аспекты нового для общества процесса - глобального транзита, определяемого М.Г. Федотовой как «переход из одного состояния общества в качественно другое, сопровождающееся изменениями в структуре и функционировании как на локальном, так и на глобальном уровнях социального развития» [26, с. 28].

Модернизация и транзитивность социальных структур, по мнению руководителя Саратовской философской школы исследования социальных рисков профессора В.Б. Устьянцева, приводят к «повышению сложности многоуровневых социальных систем». Данные процессы, происходящие одновременно с глобализацией, информатизацией, изменением мировоззрения человека и свидетельствующие о состоянии перехода общества в новое качество, формируют системные риски, определяемые В.Б. Устьянцевым как «многомерное проявление опасности для общественной и частной жизни, опасности, таящей преимущественно неблагоприятные последствия для институционального порядка и повседневного существования человека» [27, с. 425]. Поэтому можем констатировать очевидное желание социума упорядочить происходящие изменения, минимизировать риски, что обусловливает ход модернизации в направлении развития социальных инноваций.

Преобладающим фактором цивилизационного развития является способ хозяйствования, т. е. экономический фактор. Однако хозяйственная деятельность - это одна из форм деятельности социума наряду, например, с культурной, которая в приведённых выше трактовках принимается во внимание, но имеет второстепенное значение в отличие от трактовки И. Канта, согласно которой именно культура первична, а потому определяет развитие социума.

Смена позиций в связке «культура-цивилизация» на противоположные чревата индивидуальными и социальными рисками: это, например, манипулирование сознанием, а также другие формы использования человека и социума в качестве средства для достижения цивилизационных целей, которые могут быть направлены не на благо всего человечества, а на достижение личных целей людей, сообществ или государств, в руках которых сосредоточено наибольшее количество технологий (как хозяйственных, так и социальных), направленных на манипулирование отдельными индивидами и социумом в целом. Таковыми, например, могут быть некоторые информационнокоммуникативные технологии.

Существует ли альтернатива манипулятивным технологиям? Возможно, да. Какая? Если проследить процесс организации социальных технологий, можно выявить основной фактор социально-экономического и социального взаимодействия в инновационном пространстве социума и благодаря ему определить искомую альтернативу.

Социальные технологии определяются исследователями как, во-первых, «развитый, детализированный алгоритм действий, опыт успешного решения социально-значимой задачи... Во-вторых, как специфическая человеческая деятельность, направленная на оптимизацию социальных процессов, общественных организаций» [28, с. 79]. Инновационные социальные технологии есть качественно преобразованные социальные технологии, которые в первую очередь нацелены на достижение эффективности управления социальными процессами (частным случаем является их применение, направленное на получение экономического результата в виде финансовой прибыли). В то же время нужно понимать, что любые технологии - это средства для достижения целей, поэтому сами по себе не могут быть оценены ни положительно, ни отрицательно. Этическую характеристику они приобретают, исходя из характера целей достижения. Если цель применения 
социальных технологий - достижение общественного блага, то, скорее всего, общество одобрит и признает такие социальные инновации. Поэтому социальные инновации имеют не только улучшающую функцию. А это значит, что они могут быть направлены не только на прогрессивное, но и регрессивное развитие.

Развитие есть качественное изменение, направленность которого определяется преимущественно внутренними особенностями объекта развития. Наряду с этим при рассмотрении объекта в качестве системы она, как отмечает Е.Н. Князева, определяется средой и создаёт среду, которая, в свою очередь, влияет на систему, конструирует её. «Невозможно инновировать систему, не изменяя среду, и наоборот. Этот феномен взаимной связи называют энактивизмом» [29, с. 34]. Другими словами, свойства сложной системы и среды, в которую она встроена, взаимно определяют друг друга.

По мнению профессора В.А. Гуторова, идея социального прогресса, обусловленного научным прогрессом, возникла ещё в XVII в. и принадлежит философу Френсису Бэкону, понимавшему технологии в качестве способов практического применения достижений науки. С этого времени многие сторонники идеи социального прогресса, модернизируя её, указали на большое значение социокультурных факторов, необходимых для прогрессивного развития общества [30]. Взаимосвязь этих факторов можно считать проявлением феномена энактивизма, необходимого для инновационного развития общества.

Как же общество может определить безопасность и прогрессивность социальных инноваций? Чаще всего данный вопрос решается на темпоральной основе, когда на протяжении некоторого периода времени социальная самоорганизация производит отбор социально значимых ценностей, способов функционирования. По мнению современного французского философа Пьера Бурдьё, основным критерием такого отбора является «символический капитал» как «кредит доверия» или «капитал чести и престижа», облегчающий акт социального обмена, а также участвующий в воспроизводстве и поддержании социального взаимодействия [31, с. 231].

Современные российские исследователи подтверждают значимость данного социального критерия при отборе инноваций. Как отмечают И. Краснопольская и И. Мерсиянова, «важнейшими условиями включения общественности в производство социальных инноваций становятся формирование положительных установок, связанных с участием в социальных практиках гражданского общества, и широкое распространение его ценностей... На вовлечённость россиян в общественно полезные виды деятельности влияют установки на доверие, объединение, взаимопомощь и т. д.» $[18$, c. 47]. Поэтому можно согласиться с мнением о том, что социальные инновации являются «гибридным концептом, предполагающим взаимодействие государства, гражданского общества и рынка в целях удовлетворения актуальных и легитимных социальных потребностей... Основой социальных инноваций называют потенциал гражданского участия в сопроизводстве социальных услуг» [18, с. 44]. Данная точка зрения подтверждается современными исследованиями. Например, Н.С. Розов, изучивший динамику расцветов и распадов обществ, выявил фактор расцвета: «в обществах, переживающих расцвет, на первый план всегда выходит сотрудничество (кооперация)» $[32$, c. 150]. На наш взгляд, именно доверие определяет вовлечённость (включённость) людей в отношения сотрудничества, а значит и в социальные процессы в целом. Наличие доверия к инновациям, в том числе социальным, способствует развитию общества.

Понятие «доверие» определяется исследователями исходя из сферы его функционирования - социальной, политической и др. В социальном смысле доверие есть «возникающее в рамках определенного сообщества ожидание того, что его члены будут вести себя нормально и честно, проявляя готовность к взаимопомощи в соответствии с 
общепринятыми нормами, культурными традициями, обычаями, общими этическими ценностями» [33]. Социолог А. Селигмен уверен в том, что доверие поддерживает социальный порядок в долговременной перспективе [34]. Социальный порядок означает наличие в обществе определённой структуры, образующей пространство социума.

С позиций структурализма П. Бурдьё, социальное пространство - это «структура рядоположенности социальных позиций», т. е. среда, в которой осуществляются социальные отношения. Его место «может быть охарактеризовано через его относительное положение по сравнению с другими местами (выше, ниже, между и др.) и через дистанцию, отделяющую это место от других» [35, с. 49-50]. Социальное деление в пространстве функционирует как «ментальная структура» [35, с. 51], т. к. социальное пространство есть не физическое, а «абстрактное пространство, конституированное ансамблем подпространств или полей (экономическое поле, интеллектуальное поле и др.), которые обязаны своей структурой неравному распределению отдельных видов капитала» [35, с. 53-54] - экономического, культурного, социального. Их ценность определяется благодаря символическому капиталу, который становится ключевым в этой борьбе между социальными группами (классами) за господство. Структурируя социальное пространство на основании характеристик господства и подчинения, П. Бурдье выделил в обществе два класса: «бизнесмены» (те, у кого много экономического капитала, но мало культурного) и «интеллектуалы» (те, у кого много культурного, но мало экономического капитала) [35].

На основе учения П. Бурдьё была разработана новая теория общества символического капитализма, согласно которой основным способом производства в нём является символический капитал как стратегия социального функционирования посредством доверия. Основными составляющими символического капитала являются имидж и репутация. Социальная стратификация этого общества по форме напоминает сеть или ризому, состоящую из социальных групп, образованных и пересекающихся в сетевые узлы на основе общих интересов или позиций [36].

Сетевая структура общества, по мнению Е.С. Куркиной и Е.Н. Князевой, является наиболее эффективной для осуществления инновационной деятельности, т. к. обладает высокой степенью гибкости, открытости, позволяющих быстрее адаптироваться к изменениям внешней среды [37, с. 18]. В рамках упомянутой выше концепции энактивности (т. е. вдействования в среду) инновации рождаются социальными средами, которые, эволюционируя, приобретают новые качества, что свидетельствует об активизации в сетевом обществе процесса коэмерджентности - «взаимной активности системы и среды и согласованное и взаимообусловленное возникновение у них новых свойств» [29, с. 35-36]. Поскольку любое пространство деятельности людей организовано аналогично социальному пространству, то инновационное пространство (в терминологии П. Бурдье - поле науки [38]) есть вид социального пространства.

Следовательно, инновационное пространство есть инвариант социального пространства; в связи с социальной детерминированностью инновационного пространства его следует определять, исходя из особенностей функционирования социального пространства. Поэтому понятие «инновационное пространство общества» есть форма социальной самоорганизации, направленной на развитие общественных отношений, осуществляемое посредством инновационных преобразований.

В связи с тем, что инновации - это средства или способы практической деятельности людей, а социум, согласно П. Бурдье, структурирован посредством практик [35], в которых «символический капитал» является индикатором социального обмена, то «символический капитал» есть основной фактор самоорганизации инновационного 
пространства социума, способствующий выявлению жизнеспособных и эффективных для развития социума инноваций. В связи с чем альтернативой манипуляционного управления социумом является социальная самоорганизация, осуществляемая посредством «символического капитала» как «кредита доверия».

Как видим, процессы создания и продвижения инноваций в экономической сфере напрямую обусловлены социальными факторами, основным из которых является «кредит доверия». Модернизация процессов управления социумом приводит к развитию социальных инноваций, необходимых в совершенствовании социального взаимодействия развивающегося общества.

\section{Выводы и результаты}

Таким образом, в данной работе была поставлена цель - изучение и определение инновационного пространства современного общества с позиций философии.

Для достижения цели были решены следующие задачи: 1) проанализированы основные теоретические подходы к исследованию инновационного пространства, проанализировано развитие теории инноваций и инноватики; 2) определён основной фактор социально-экономического и социального взаимодействия в инновационном пространстве общества; 3) выявлена взаимосвязь модернизации с социальными инновациями.

В результате проведённого исследования были получены новые результаты:

1. Выявлен основной фактор социально-экономического и социального взаимодействия в инновационном пространстве общества - «символический капитал» как «кредит доверия», так как доверие определяет вовлечённость (включённость) людей в социальный процесс. Наличие доверия к инновациям, в том числе социальным, способствует развитию общества.

2. Впервые автором определено понятие «инновационное пространство общества» как «форма социальной самоорганизации, направленной на развитие общественных отношений, осуществляемое посредством инновационных преобразований».

Можно сделать вывод о том, что инновационное пространство есть инвариант социального пространства; в связи с социальной детерминированностью инновационного пространства его следует определять, исходя из особенностей функционирования социального пространства. В этом случае возможно получение более полного представления об инновационной системе, что в перспективе позволит разработать модели управления инновационным пространством, способствующие прогрессивному развитию общества. Полученные результаты исследования могут быть полезны в социальных, управленческих, экономических, философских науках.

\section{СПИСОК ЛИТЕРАТУРЫ}

1. Философский энциклопедический словарь / гл. ред. Л.Ф. Ильичев, П.Н. Федосеев. - М.: Сов. Энциклопедия, 1983. - 836 с.

2. Суровцев И.С. Инновации и инновационная деятельность: толковый терминологический словарь. Воронеж: Цифровая полиграфия, 2015. - $71 \mathrm{c.}$

3. Druker H.F. Management Challeges for the 21 Century. - N.Y.: Harper Business, 1999. - 299 p.

4. Красоченкова Н.П. Национальное инновационное пространство в экономике знаний: понятие, содержание и формирование // Управленческие науки. - 2016. - № 2. - С. 6-11.

5. Красоченкова Н.П. Национальное инновационное пространство в экономике знаний // Стратегические решения и риск-менеджмент. - 2016. - № 5 (98). - С. 44-48.

6. Воейкова О.Б., Лячин В.И. Категориальное определение инновационного пространства // Сибирский журнал науки и технологий. - 2015. - Т. 16. - № 4. - С. 1014-1021.

7. Семёнов А.В. Основные факторы и свойства инновационной среды // Российское предпринимательство. - 2012. - № 18 (240). - С. 54-59. 
8. Давыдов А.А. К вопросу об определении понятия «общество» // Социологические исследования. 2004. - № 2 (238). - С. 12-23.

9. Липсиц И.В. Экономика. - М.: Омега-Л, 2006. - 656 с.

10. Романов В.Л. Социально-инновационный вызов государственному управлению // Инноватика государственного управления: прорыв в будущее. Материалы научно-практической конференции. - М.: Проспект, 2006. - C. 66-71. URL: http://spkurdyumov.ru/biology/socialno-innovacionnyj-vyzovgosudarstvennomu-upravleniyu/2/ (дата обращения 01.07.2019).

11. Пригожин А.И. Нововведения: стимулы и препятствия. - М.: Политиздат, 1989. - 272 с.

12. Кондратьев Н.Д. Проблемы экономической динамики. - М.: Экономика, 1989. - 523 с.

13. Schumpeter J. Theorie der wirtschaftlichen Entwicklung. - Leipzig: Verlag von Duncker \& Humblot, 1912. - 548 s.

14. Mensch G. Das Technologische Patt: Innovationen überwinden die depression. - Frankfurt am Main: Umschau Verlag, 1975. - $155 \mathrm{~s}$.

15. Кужева С.Н. Из истории развития теории нововведений и управления инновациями // Инновационная экономика и общество. - 2015. - № 2 (8). - С. 2-12.

16. Пригожин И., Стенгерс И. Время, хаос, квант // АНО «Центр междисциплинарных исследований», сайт С.П. Курдюмова. URL: http://spkurdyumov.ru/philosophy/vremya-xaos-kvant/2/ (дата обращения 1.07.2019).

17. Розов Н.С. Когда началась эпоха Модерна и закончилась ли она? // Сибирский философский журнал. - 2018. - Т. 16. - № 2. - С. 63-74.

18. Краснопольская И., Мерсиянова И. Гражданское общество как среда производства и распространения социальных инноваций // Форсайт. - 2014. - Т. 8. - № 4. - С. 40-53.

19. Кант И. Основы метафизики нравственности // Сочинения в шести томах. - Т. 4. - Ч. 1. - М.: Мысль, 1965. - C. 211-310.

20. Spengler O. Der Untergang des Abendlandes: Umrisse einer Morphologie der Weltgeschichte. - Munchen: C.H. Beck'sche Verlagbuchandlung, 1922. - 603 s.

21. Устьянцев В.Б. Пространство цивилизаций в контексте смены типов рациональности // Философия и общество. - 2007. - № 3. - С. 81-98.

22. McLuhan M. The Gutenberg Galaxy: The Making of Typographic Man. - Toronto: University of Toronto Press, 1962. - $294 \mathrm{p}$.

23. Bell D. The Social Framework of the Information Society. - Oxford: Blackwell, 1980. - $315 \mathrm{p}$.

24. Toffler A. Power shift: Knowledge, Wealth, and Violence at the Edge of the 21st Century. - New York: Bantam Books, 1990. - 586 p.

25. Baudrillard J. La societe de consummation. Ses mythes, ses structures. - Paris: S.Y.P.P., 1970. - 320 p.

26. Федотова М.Г. К содержанию понятия «транзитивное общество» // Вестник Вятского государственного гуманитарного университета. - 2010. - № 1 (4). - С. 28-31.

27. Устьянцев В.Б. Системные риски переходного общества // Известия Саратовского университета. Серия «Философия. Психология. Педагогика». - 2017. - Т. 17. - Вып. 4. - С. 425-429.

28. Асеева И.А. Социальные технологии как влиятельный фактор развития технонауки и общества // Биосферная совместимость: человек, регион, технологии. - 2016. - № 4 (16). - С. $79-86$.

29. Князева Е. Энактивность систем и сред инновационного развития // Наука и инновации. -2012. № 10 (116). - С. 34-36.

30. Гуторов В.А. О некоторых тенденциях интерпретации концепции прогресса в современной социальной теории // Вопросы философии. - 2017. - № 12. - С. 32-43.

31. Bourdieu P. Le sens pratique. - Paris: Les Editions de Minuit, 1980. - 475 p.

32. Розов Н.С. Динамика расцветов и распадов обществ: на пути к охватывающей парадигме // Общественные науки и современность. - 2016. - № 4. - С. 146-158.

33. Fukuyama F. Trust: The Social Virtues and the Creation of Prosperity. - New York: Free Press, 1995. - 457 p.

34. Seligman A. The Problem of Trust. - Princeton, N.Y.: Princeton University Press, 1997. - 231 p.

35. Бурдье П. Социология социального пространства - М.: Институт экспериментальной социологии; СПб.: Алетейя, 2007. - 288 с.

36. Демидова М.В. Социальная стратификация в условиях символического капитализма: философский подход // Известия Томского политехнического университета. - 2014. - Т. 325. - № 6. - С. 75-80.

37. Куркина Е.С., Князева Е.Н. Структурные трансформации в процессе эволюции общества: от иерархических структур к сетевым // Сложные системы. - 2017. - № 4 (25). - С. 4-26.

38. Бурдьё П. Поле науки // Социология под вопросом. Социальные науки в постструктуралистской перспективе. - M.: Praxis, 2005. - C. 15-56.

Поступила 14.07.2019 г. 
UDC 1/14:316+422:316.3

\title{
INNOVATIVE SPACE AND SOCIETY: DEFINITIONS, DEVELOPMENT FACTORS
}

\author{
Marina V. Demidova, \\ demidovamv@rambler.ru \\ Saratov State University, \\ 83, Astrakhanskaya street, Saratov, 410012, Russia.
}

Marina V. Demidova, Cand. Sc., master, Saratov State University.

The relevance. The development of science and technology has an impact on the structure and organization of modern society. This contributes to the development of the innovation space. The study of the category «innovative space» is currently limited mainly by the framework of economic science. Therefore, researchers do not take into account the laws of social development. Limiting innovation space to an economic framework can lead to the risk of identifying the assessment of social development with the assessment of economic development of society. Therefore, it is necessary to determine the innovative space from the sociophilosophical positions. The aim of the research is to study and determine the innovative space of modern society from the standpoint of philosophy. Methods. Interdisciplinary specificity of innovative transformations focuses on consideration of the studied issues in the transdisciplinary aspect: that is, on the basis of philosophical approaches and methods of research of innovative space of society. Therefore, the methodological basis of research work amounted to dialectical, culture-civilizational, socio-synergetic approach, scientific methods, the concept of enactivety. Results. The evolution of innovations in relation to the development of society is traced. The main factor of socio-economic and social interaction in the innovative space of society is «symbolic capital» as "trust», as trust determines the involvement (involvement) of people in the social process. The presence of trust in innovation, including social, contributes to the development of society. By identifying the relationship of modernization with social innovation for the first time the author defines the concept of innovative space of society» as «a form of social self-organization aimed at the development of social relations, carried out through innovative reforms. Conclusion. Innovative space is an invariant of social space; in relation to social conditionality of innovative space, it should be determined on the basis of the peculiarities of the functioning of social space. In this case, we will be able to get a better idea of the innovation system, which in the future will allow us to develop models of innovation space management, contributing to the progressive development of society. The results of the study can be useful in social, managerial, economic, philosophical Sciences.

Key words: Innovation, innovative space, development of society, symbolic capital, trust, modernization, social technology, factors of development, social space, social self-organization, social progress, Pierr Bourdieu, enactivety.

\section{REFERENCES}

1. Filosofskiy entsiklopedicheskiy slovar [Philosophical encyclopedic dictionary]. Eds. L.F. Ilichev, P.N. Fedoseev. Moscow, Sovetskaya entsiklopediya Publ., 1983. 836 p.

2. Surovtsev I.S. Innovatsii i innovatsionnaya deyatelnost: tolkovy terminologicheskiy slovar [Innovation and innovation: an explanatory vocabulary]. Voronezh, Tsyfrovaya poligrafiya Publ., 2015. $71 \mathrm{p}$.

3. Druker H.F. Management Challeges for the 21 Century. N.Y., Harper Business, 1999. 299 p.

4. Krasochenkova N.P. National innovation space in the knowledge economy: definition, content and formation. Upravlencheskie nauki, 2016, no. 2, pp. 6-11. In Rus.

5. Krasochenkova N.P. Natsionalnoe innovatsionnoe prostranstvo v ekonomike znaniy [National innovation space in the knowledge economy]. Strategicheskie resheniya i risk-menedzhment, 2016, no. 5 (98), pp. 44-48. 
6. Voeykova O.B., Lyachin V.I. The categorical definition of innovation space. Sibirskiy zhurnal nauki $i$ tekhnologii, 2015, vol. 16, no. 4, pp. 1014-1021. In Rus.

7. Semenov A.V. Osnovnye faktory i svoystva innovatsionnoy sredy [The main factors and properties of the innovation environment]. Rossiyskoe predprinimatelstvo, 2012, no. 18 (240), pp. 54-59.

8. Davydov A.A. K voprosu ob opredelenii ponyatiya «obshchestvo» [On the question of the definition of «society2]. Sotsiologicheskie issledovaniya, 2004, no. 2 (238), pp. 12-23.

9. Lipsits I.V. Ekonomika [The Economy]. Moscow, Omega-L Publ., 2006. 656 p.

10. Romanov V.L. Sotsialno-innovatsionniy vyzov gosudarstvennomu upravleniyu [Social and innovative challenge to public administration]. Materialy nauchno-prakticheskoy konferentsii. Innovatika gosudarstvennogo upravleniia: proryv v budushchee [Innovation of public administration: breakthrough into the future. Materials of scientific and practical conference]. Moscow, Prospekt Publ., 2006. pp. 66-71. Available at: http://spkurdyumov.ru/biology/socialno-innovacionnyj-vyzov-gosudarstvennomuupravleniyu/2/ (accessed 1 July 2019).

11. Prigozhin A.I. Novovvedeniya: stimuly i prepiatstviya [Innovations: incentives and barriers]. Moscow, Politizdat Publ., 1989. 272 p.

12. Kondratev N.D. Problemy ekonomicheskoy dinamiki [Problems of economic dynamics]. Moscow, Ekonomika Publ., 1989. 523 p.

13. Schumpeter J. Theorie der wirtschaftlichen Entwicklung [Theory of Economic Development]. Leipzig, Verlag von Duncker \& Humblot, 1912. 548 p. In Ger.

14. Mensch G. Das Technologische Patt: Innovationen überwinden die depression [The technological stalemate: innovations overcome depression]. Frankfurt am Main, Umschau Verlag, 1975. 155 p. In Ger.

15. Kuzheva S.N. Iz istorii razvitiya teorii novovvedeniy i upravleniya innovatsiyami [From the history of innovation theory and innovation management]. Innovatsionnaya ekonomika i obshchestvo, 2015, no. 2 (8), pp. $2-12$.

16. Prigozhin I., Stengers I. Vremya, khaos, kvant. ANO «Tsentr mezhdistsiplinarnykh issledovaniy», sayt S.P. Kurdyumova. Available at: http://spkurdyumov.ru/philosophy/vremya-Xaos-kvant/2/ (accessed 1 July 2019).

17. Rozov N.S. When did the modern era begin and did it end?. Sibirskiy filosofskiy zhurnal, 2018, vol. 16, no. 2, pp. 63-74. In Rus.

18. Krasnopolskaya I., Mersiyanova I. Civil Society as an environment for production and diffusion of social innovation. Foresight and STI Governance, 2014, vol. 8, no. 4, pp. 40-53. In Rus.

19. Kant I. Osnovy metafiziki nravstvennosti [Fundamentals of the metaphysics of morality]. Sochineniya $v$ shesti tomakh [Works in six volumes]. Vol. 6, ch. 1. Moscow, Mysl Publ., 1965. pp. 211-310.

20. Spengler O. Der Untergang des Abendlandes: Umrisse einer Morphologie der Weltgeschichte [The Fall of the West: Outlines of a Morphology of World History]. Munchen, C.H. Beck'sche Verlagbuchandlung, 1922. 603 p. In Ger.

21. Ustyantsev V.B. Prostranstvo tsivilizatsii v kontekste smeny tipov ratsionalnosti [Space of civilizations in the context of changing types of rationality]. Filosofiya i obshchestvo, 2007, no. 3, pp. 81-98.

22. McLuhan M. The Gutenberg Galaxy: The Making of Typographic Man. Toronto, University of Toronto Press, 1962. $294 \mathrm{p}$.

23. Bell D. The Social Framework of the Information Society. Oxford, Blackwell, 1980. 315 p.

24. Toffler A. Power shift: Knowledge, Wealth, and Violence at the Edge of the $21^{\text {st }}$ Century. New York, Bantam Books, 1990. 586 p.

25. Baudrillard J. La societe de consummation. Ses mythes, ses structures [The consumer society. His myths, his structures]. Paris, S.Y.P.P., 1970. 320 p. In French.

26. Fedotova M.G. To the content of the concept «transitive society». Vestnik Vyatskogo gosudarstvennogo gumanitarnogo universiteta, 2010, no. 1 (4), pp. 28-31. In Rus.

27. Ustyantsev V.B. Systemic risks of a society in transition. Izvestiya Saratovskogo universiteta. Seriya «Filosofiya. Psikhologiya. Pedagogika», 2017, vol. 17, Iss. 4, pp. 425-429. In Rus.

28. Aseeva I.A. Social technologies as an influential factor in the development of technoscience and society. Biosfernaya sovmestimost: chelovek, region, tekhnologii, 2016, no. 4 (16), pp. 79-86. In Rus.

29. Knyazeva E. Enaktivnost sistem i sred innovatsionnogo razvitiya [Enactively systems and environments of innovation development]. Nauka i innovatsii, 2012, no. 10 (116), pp. 34-36.

30. Gutorov V.A. On some trends in the interpretation of the concept of progress in modern social theory. Voprosy filosofii, 2017, no. 12, pp. 32-43. In Rus.

31. Bourdieu P. Le sens pratique [Practical Sense]. Paris, Les Editions de Minuit, 1980. 475 p. In French.

32. Rozov N.S. Dynamics of flourishes and decays societies: towards embracing the paradigm. Obshchestvennye nauki i sovremennost, 2016, no. 4, pp. 146-158. In Rus. 
33. Fukuyama F. Trust: The Social Virtues and the Creation of Prosperity. New York, Free Press, 1995. 457 p.

34. Seligman A. The Problem of Trust. Princeton, N.Y., Princeton University Press, 1997. 231 p.

35. Burde P. Sotsiologiya sotsialnogo prostranstva [Sociology of social space]. Moscow, Institut eksperimentalnoy sotsiologii; St. Petersburg, Alateya Publ., 2007. 288 p.

36. Demidova M.V. Social stratification under symbolic capitalism: a philosophical approach. Bulletin of the Tomsk Polytechnic University, 2014, vol. 325, no. 6, pp. 75-80. In Rus.

37. Kurkina E.S., Knyazeva E.N. Structural transformations in the process of society evolution: from hierarchical to network structures. Slozhnye sistemy, 2017, no. 4 (25), pp. 4-26. In Rus.

38. Burde P. Pole nauki [Field of science]. Sotsiologiya pod voprosom. Sotsialnie nauki v poststrukturalistskoy perspective [Sociology is in the question. Social sciences in a poststructuralist perspective]. Moscow, Praxis Publ., 2005. pp. 15-56.

Received: 14 July 2019. 